\title{
Characteristics of carbonyl compounds emission from a diesel-engine using biodiesel-ethanol-diesel as fuel
}

\author{
Xiaobing Pang ${ }^{\mathrm{a}}$, Xiaoyan Shi ${ }^{\mathrm{a}}$, Yujing $\mathrm{Mu}^{\mathrm{a}, *}$, Hong $\mathrm{He}^{\mathrm{a}}$, Shijin Shuai ${ }^{\mathrm{b}}$, \\ $\mathrm{Hu}$ Chen ${ }^{\mathrm{b}}$, Rulong $\mathrm{Li}^{\mathrm{b}}$ \\ ${ }^{a}$ State Key Laboratory of Environmental Chemistry and Ecotoxicology, Research Center for Eco-environmental Sciences, \\ Chinese Academy of Sciences, Beijing 100085, China \\ ${ }^{\mathrm{b}}$ State Key Laboratory of Automotive Safety and Energy, Tsinghua University, Beijing 100084, China
}

Received 3 January 2006; received in revised form 30 May 2006; accepted 11 June 2006

\begin{abstract}
Characteristics of carbonyl compounds (carbonyls) emissions from biodiesel-ethanol-diesel (BE-diesel) were investigated in a Commins-4B diesel engine and compared with those from fossil diesel. Acetaldehyde was the most abundant carbonyls in the exhaust, followed by formaldehyde, acetone, propionaldehyde and benzaldehyde. Apliphatic carbonyls emitted from BE-diesel were higher than those from diesel fuel, while formaldehyde and aromatic carbonyls were less than those from diesel fuel. Total carbonyls emissions from BE-diesel were 1-12\% higher than those from diesel fuel depending on engine operating conditions. The effects of engine speed and load level were also investigated carefully. It was found that total carbonyls emission was in positive correlation with the engine speed. During the constant speed/ varying load tests, minimum total carbonyls emission was found at $50 \%$ load. Compared with fossil diesel, the BE-diesel was observed to significantly reduce $\mathrm{PM}$ emission and increase slightly $\mathrm{NO}_{x}$ emission.
\end{abstract}

(C) 2006 Elsevier Ltd. All rights reserved.

Keywords: Carbonyl compounds; Biodiesel; Ethanol; Diesel

\section{Introduction}

The global energy crisis promotes many countries to search for alternative energy sources. Two oxygenated biofuels (biodiesel and ethanol) have received intensive attention as potential alternative fuels for diesel engines due to their renewable property and friendliness to environment. Biodiesel

\footnotetext{
*Corresponding author. Tel.: + 861062849125 ; fax: +861062923563 .

E-mail addresses: yjmu@rcees.ac.cn, yjmu@mail.rcees.ac.cn (Y. Mu).
}

is an oxygenated diesel fuel made from vegetable oils and animal fats by conversion of the triglyceride fats to esters via transesterification. It has properties similar to those of fossil diesel such that it can be substituted for diesel fuel with little or no engine modification. Many studies clearly indicated that biodiesel can substantially reduce the emissions of PM and CO (Cardone et al., 2002; Wang et al., 2000; Sharp et al., 2000a). Ethanol is a low cost oxygenated compound with high oxygen content $(35 \%)$ that has been used in ethanol-diesel (E-diesel) fuel blends. The use of ethanol in diesel fuel can yield significant reduction of PM emissions and 
reduce toxic gases such as $\mathrm{CO}$, sulfur oxides $\left(\mathrm{SO}_{x}\right)$, from exhaust emissions comparing with fossil diesel (Ajiv et al, 2000; Fernando and Hanna, 2004). However, a major drawback with E-diesel is that ethanol is immiscible in diesel over a wide range of temperatures (Gerdes and Suppes, 2001). Studies have revealed that biodiesel can be used successfully as an amphiphile to stabilize ethanol in diesel and the biodiesel-ethanol-diesel (BE-diesel) blend fuel can be stable well below sub-zero temperatures (Fernando and Hanna, 2004; Makareviciene et al., 2005). BE-diesel is a new form of biofuel blend from renewable material that has energy values comparable to those of fossil fuels and has superior lubricity and environmentally friendly characteristics. It has been suggested that the biodiesel and ethanol blends can be an optimized oxygenated agent for diesel fuels (McCormick and Parish, 2001). Shi et al. (2005) and Ali et al. (1995) tested four and 12 different blends of biodiesel, ethanol and diesel, respectively in diesel engine to investigate the regulated emission and the performance of engine. It was found that particulate matters (PM), total hydrocarbon (THC) and CO were substantially reduced for $\mathrm{BE}$-diesel in comparison with fossil diesel. However, the above studies scarcely investigate the unregulated emission, e.g. carbonyl compounds (carbonyls) emissions.

The atmospheric carbonyls in urban area are mainly emitted by vehicular exhaust (Grosjean et al., 2001). Some carbonyls such as formaldehyde, acetaldehyde, acrolein, and methyl ethyl ketone are toxic, mutagenic, and even carcinogenic to human body (Carlier et al., 1986). Furthermore, carbonyls play a critical role on the tropospheric chemistry. They are important precursors to free radicals $\left(\mathrm{HO}_{x}\right)$, ozone, and peroxyacylnitrates (PAN) (Carter, 1995; Gaffney et al., 1997). Therefore, carbonyls emission from vehicular exhaust is of special importance to study, especially from the vehicles fueled by alternative fuels such as biodiesel, biodiesel-diesel, E-diesel, or E-gasoline (Cardone et al., 2002; Magnusson et al., 2002; Poulopoulos et al., 2001; Sharp et al., 2000b). For BE-diesel, to our knowledge, there were few studies concerning the carbonyls emission.

In the current study, the objective was to study the carbonyls emissions and regulated emissions from a diesel engine using fuel blends of fossil diesel, methyl soyate (biodiesel), and ethanol in comparison with fossil diesel under various engine operating conditions. The influences of engine speeds and load levels on carbonyls emissions were also investigated in this study.

\section{Experiment}

\subsection{Test fuels}

Two test fuels were used in this study. The first was commercial Chinese in-use diesel fuel without any oxygenated additives, which was used as a reference fuel and a base fuel for the preparation of ethanol-biodiesel-diesel blends. The second was ethanol-biodiesel-diesel mixture containing 5\% ethanol, $20 \%$ biodiesel, and $75 \%$ diesel $\mathrm{v} / \mathrm{v}$, respectively, and is noted as BE-diesel hereinafter. The properties of the fuels and additives used are presented in Table 1.

\subsection{Engine and experimental procedure}

All tests were performed on a Cummins-4B diesel engine (4-cylinder, 3.92 L displacement, 17.5:1 compression ratio). A Zöllner electric eddy dynamometer (Germany) was coupled to the engine and used to measure the engine power. Prior to running each experiment, the engine was fully warmed. Two types of experimental conditions were carried out in this study: constant load/varying speed tests (engine performance at various speeds with full load) and constant speed/varying load tests (engine performance at steady speed, $1800 \mathrm{rpm}$, with varying loads).

\subsection{Carbonyls analysis}

The sampling and analysis of carbonyls in exhaust gas were based on the EPA Method-TOP 11(US EPA, 1999). Carbonyls were collected at the outlet of exhaust emission by two 2,4-dinitrophenylhydrazine (DNPH)-coated silica gel cartridges

Table 1

Properties of diesel and BE-diesel

\begin{tabular}{lll}
\hline Properties & Diesel & BE-diesel \\
\hline Density, $\mathrm{g} \mathrm{mL}^{-1}$ at $20^{\circ} \mathrm{C}$ & 0.84 & 0.845 \\
Oxygen $(\mathrm{wt} \%)$ & $\mathrm{n} / \mathrm{a}$ & 3.9 \\
Carbonate $(\mathrm{wt} \%)$ & 87 & 83 \\
Hydrogen $(\mathrm{wt} \%)$ & 13 & 12.8 \\
Cetane number & 46 & 45 \\
Gross heat content $\left(\mathrm{mJ} \mathrm{kg}^{-1}\right)$ & 42.5 & 40.9 \\
Viscosity $\left(\mathrm{cS} 40^{\circ} \mathrm{C}\right)$ & 3.11 & 3.04 \\
\hline
\end{tabular}


(Waters, USA) in series for $3 \mathrm{~min}$. The air flow rates through the DNPH-coated cartridges were typically $0.8 \mathrm{~L} \mathrm{~min}^{-1}$. The carbonyls are highly reactive in the presence of 2,4-dinitrophenylhydrazine and chemical transform to the corresponding hydrazones. The exhaust of each operating condition was sampled twice. After sampling, the sampled cartridges were eluted by $5.0 \mathrm{~mL}$ acetonitrile and analyzed within $48 \mathrm{~h}$ by a HPLC system (Hewlett-Packard 1050 equipped with a UV/Vis detector at $360 \mathrm{~nm}$ ). The formed carbonyl-DNPH derivatives were separated on a Thermo ODS Hypersil column $(5 \mu \mathrm{m}$, $250 \times 5.0 \mathrm{~mm}$ ). Acetonitrile and water were used as mobile phases according to the following procedure: $0-14 \mathrm{~min}$ from $60 \%$ to $100 \%$ acetonitrile, and $40 \%$ to $0 \%$ water. The flow rate was $1.0 \mathrm{~mL} \mathrm{~min}^{-1}$ and the injection volume was $10 \mu \mathrm{L}$. The RSD of analysis for five parallel samples collected at one engine operating condition was below $8 \%$.

In addition, Alliance 2695/ZQ $4000 \mathrm{HPLC} / \mathrm{MS}$ (Waters, USA) with APCI in negative model was used to qualify the different carbonyl-DNPHs by their quasi-molecular ions. For identification and quantification, external reference standards solutions in five different concentrations of the carbonyl-DNPHs were either synthesized or bought from Supelco.

\subsection{Analysis of regulated emissions and ethanol}

An AVL CEB-11 analyzer was used to measure continuously the concentrations of $\mathrm{NO}_{x}, \mathrm{THC}, \mathrm{CO}$ and $\mathrm{CO}_{2}$ on line in the exhaust. The relative standard deviations of the analyzer, are below $1 \%$ for $\mathrm{NO}_{x}$, below $5 \%$ for $\mathrm{CO}$, below $3 \%$ for $\mathrm{THC}$ and below $0.2 \%$ for $\mathrm{CO}_{2}$. Total PM was measured by an AVL PM analyzer and collected on PTFE-coated glass filter (AVL, USA). The filter was conditioned at $25^{\circ} \mathrm{C}$ and $50 \%$ humidity, and it was weighed before and after the sampling procedure. The ethanol in exhaust gas was analyzed by gas chromatography with flame ionization detection (GC-FID).

\section{Results and discussion}

\subsection{Carbonyl emissions}

\subsubsection{Comparison of different carbonyls}

Thirteen carbonyls were identified and quantified in the exhaust, including formaldehyde, acetaldehyde, acetone, butyraldehyde, propionaldehyde, methylacrolein, crotonaldehyde, benzaldehyde, valeraldehyde, isovaleraldehyde, $m$-tolualdehyde, p-tolualdehyde, hexaldehyde, 2,5-dimethylbenzaldehyde. The concentrations of those carbonyls in the exhaust at different engine speeds and load levels were listed in Tables 2 and 3, respectively. It was found that acetaldehyde was by far the most abundant carbonyl in the exhaust and accounted for $28-38 \%$ of the total carbonyls concentrations for BE-diesel and 18-34\% for diesel. Formaldehyde accounted for $8-28 \%$ for BE-diesel and $13-39 \%$ for diesel. Acetone, propionaldehyde and benzaldehyde accounted for $5-13 \%, 9-15 \%$, and $2-6 \%$ for BEdiesel and $6-12 \%, 8-12 \%$, and $4-11 \%$ for diesel, respectively. Other carbonyls (methylacrolein, crotonaldehyde, valeraldehyde, isovaleraldehyde, $m$ tolualdehyde, $p$-tolualdehyde, hexaldehyde) were found in the same order of magnitude and each of them was accounted for less than $5 \%$ in total carbonyls from both BE-diesel and diesel. The total amount of $m$-tolualdehyde, $p$-tolualdehyde, hexaldehyde, and 2,5-dimethylbenzaldehyde accounted for $4-17 \%$ for BE-diesel and $9-13 \%$ for diesel, respectively (Figs. 1 and 2 ).

\subsubsection{Carbonyls emissions from BE-diesel and diesel}

As listed in Tables 2 and 3, the formaldehyde emissions from BE-diesel decreased about 10-50\% as compared to those from diesel. Formaldehyde in vehicle exhaust mainly comes from the incomplete combustion of saturated apliphatic hydrocarbonys (Magnusson et al., 2002). The lower percent of saturated apliphatic hydrocarbonys in BE-diesel might be responsible for the decrease of formaldehyde emission compared with fossil diesel. The benzaldehyde emissions from BE-diesel were 35\% to $75 \%$ less than those from diesel under most operating conditions. It should be noted that 2,5dimethylbenzaldehyde was only measured in the fossil diesel exhaust. Previous study indicated that benzaldehyde and 2,5-dimethylbenzaldehyde emissions could be directly related with the content of aromatics or olefins (Magnusson et al., 2002). The contents of aromatics and olefins in BE-diesel might be lower than those in diesel.

The acetaldehyde emissions from BE-diesel were significantly higher than those from diesel with increments about $20-78 \%$ (Fig. 3). Previous investigations reported that ethanol blend in fuel would increase acetaldehyde emission because ethanol was the main precursor of acetaldehyde in 
Table 2

Emissions of carbonyls and ethanol $\left(\mathrm{mg} \mathrm{m}^{-3}\right)$ from diesel and BE-diesel at five different engine speeds under full load

\begin{tabular}{|c|c|c|c|c|c|c|c|c|c|c|}
\hline \multirow{3}{*}{$\begin{array}{l}\text { Carbonyls and ethanol } \\
\left(\mathrm{mg} \mathrm{m}^{-3}\right)\end{array}$} & \multicolumn{10}{|c|}{ Speed (rpm) } \\
\hline & \multicolumn{5}{|c|}{ Diesel } & \multicolumn{5}{|c|}{ BE-diesel } \\
\hline & 1200 & 1600 & 2000 & 2400 & 2800 & 1200 & 1600 & 2000 & 2400 & 2800 \\
\hline Formaldehyde & 1.46 & 2.52 & 2.74 & 1.66 & 1.58 & 1.20 & 2.25 & 1.99 & 0.87 & 1.21 \\
\hline Acetaldehyde & 1.85 & 1.57 & 3.19 & 3.62 & 4.19 & 2.01 & 2.29 & 3.75 & 4.79 & 5.16 \\
\hline Acetone & 0.54 & 0.59 & 0.74 & 0.94 & 0.85 & 0.57 & 0.75 & 0.66 & 1.01 & 0.88 \\
\hline Propionaldehyde & 0.62 & 0.58 & 0.95 & 0.82 & 0.97 & 0.78 & 0.78 & 1.15 & 1.26 & 1.82 \\
\hline Crotonaldehyde & 0.15 & 0.14 & 0.78 & 0.49 & 0.64 & 0.09 & 0.29 & 0.49 & 0.45 & 0.74 \\
\hline Methylacrolein & 0.26 & 0.29 & 0.57 & 0.61 & 0.90 & 0.29 & 0.19 & 0.26 & 0.34 & 0.81 \\
\hline Butyraldehyde & 0.18 & 0.30 & 0.44 & 0.33 & 0.35 & 0.57 & 0.29 & 0.33 & 0.29 & 0.49 \\
\hline Benzaldehyde & 0.42 & 0.27 & 1.37 & 0.97 & 1.09 & 0.28 & 0.43 & 0.55 & 0.51 & 0.80 \\
\hline Isovaleradehyde & 0.30 & 0.33 & 0.23 & 0.25 & 0.36 & 0.09 & 0.35 & 0.50 & 1.13 & 0.69 \\
\hline Valeradehyde & 0.17 & 0.28 & 0.29 & 0.57 & 0.57 & 0.33 & 0.23 & 0.22 & 0.29 & 1.57 \\
\hline$m, p$-Tolualdehyde & $\mathrm{Nd}^{\mathrm{a}}$ & $\mathrm{Nd}$ & 0.38 & 0.57 & 0.57 & $\mathrm{Nd}$ & $\mathrm{Nd}$ & 0.24 & 0.24 & 0.75 \\
\hline Hexaldehyde & 0.12 & 0.12 & 0.14 & 0.13 & 0.13 & 0.13 & 0.11 & 0.12 & 0.12 & 0.11 \\
\hline 2,5-dimethylbenzaldehyde & 0.29 & 0.31 & 0.49 & 0.26 & 0.14 & $\mathrm{Nd}$ & $\mathrm{Nd}$ & $\mathrm{Nd}$ & $\mathrm{Nd}$ & $\mathrm{Nd}$ \\
\hline Total carbonyls & 6.36 & 7.31 & 12.6 & 11.23 & 12.3 & 6.34 & 7.91 & 10.27 & 11.32 & 15.03 \\
\hline Ethanol & $\mathrm{Nd}$ & $\mathrm{Nd}$ & $\mathrm{Nd}$ & $\mathrm{Nd}$ & $\mathrm{Nd}$ & 10.8 & 3.62 & 8.87 & 7.24 & 9.41 \\
\hline
\end{tabular}

${ }^{\mathrm{a}} \mathrm{Nd}$ : not detected.

Table 3

Emissions of carbonyls and ethanol $\left(\mathrm{mg} \mathrm{m}^{-3}\right)$ from diesel and BE-diesel at five load levels under stable speed (1800 rpm)

\begin{tabular}{|c|c|c|c|c|c|c|c|c|c|c|}
\hline \multirow{3}{*}{$\begin{array}{l}\text { Carbonyls and ethanol } \\
\left(\mathrm{mg} \mathrm{m}^{-3}\right)\end{array}$} & \multicolumn{10}{|c|}{ Load level (\%) } \\
\hline & \multicolumn{5}{|c|}{ Diesel } & \multicolumn{5}{|c|}{ BE-diesel } \\
\hline & 10 & 25 & 50 & 75 & 100 & 10 & 25 & 50 & 75 & 100 \\
\hline Formaldehyde & 1.79 & 1.76 & 1.39 & 2.31 & 2.63 & 0.86 & 1.64 & 1.06 & 1.85 & 1.978 \\
\hline Acetaldehyde & 3.33 & 1.98 & 1.20 & 1.12 & 2.38 & 3.88 & 2.44 & 1.37 & 1.97 & 3.009 \\
\hline Acetone & 1.12 & 0.66 & 0.61 & 0.44 & 0.73 & 1.38 & 1.11 & 0.64 & 0.80 & 0.838 \\
\hline Propionaldehyde & 1.19 & 0.90 & 0.53 & 0.52 & 0.65 & 1.12 & 1.34 & 0.62 & 0.64 & 0.728 \\
\hline Crotonaldehyde & 0.35 & 0.24 & 0.25 & 0.21 & 0.27 & 0.53 & 0.36 & 0.11 & 0.12 & 0.512 \\
\hline Methylacrolein & 0.26 & 0.17 & $\mathrm{Nd}^{\mathrm{a}}$ & 0.14 & 0.29 & 0.43 & 0.58 & 0.21 & 0.12 & 0.254 \\
\hline Butyraldehyde & 0.37 & 0.17 & 0.18 & 0.13 & 0.40 & 0.26 & 0.31 & 0.01 & 0.16 & 0.295 \\
\hline Benzaldehyde & 0.57 & 0.41 & 0.20 & 0.34 & 0.73 & 0.38 & 0.15 & 0.25 & 0.44 & 0.504 \\
\hline Isovaleradehyde & 0.18 & 0.26 & $\mathrm{Nd}$ & $\mathrm{Nd}$ & 0.42 & 0.29 & 0.39 & 0.20 & 0.15 & 0.612 \\
\hline Valeradehyde & 0.33 & 0.29 & 0.17 & 0.13 & 0.26 & 0.65 & 0.16 & $\mathrm{Nd}$ & 0.10 & $\mathrm{Nd}$ \\
\hline$m, p$-Tolualdehyde & 0.23 & 0.37 & 0.27 & 0.22 & 0.23 & 0.27 & 0.56 & 0.28 & 0.30 & 0.227 \\
\hline Hexaldehyde & 0.11 & 0.12 & 0.12 & 0.13 & 0.13 & 0.13 & 0.13 & 0.15 & 0.11 & 0.123 \\
\hline 2,5-dimethylbenzaldehyde & 0.21 & 0.17 & 0.09 & 0.22 & 0.35 & $\mathrm{Nd}$ & $\mathrm{Nd}$ & $\mathrm{Nd}$ & $\mathrm{Nd}$ & $\mathrm{Nd}$ \\
\hline Total carbonyls & 10.1 & 7.51 & 5.03 & 5.90 & 9.01 & 10.2 & 9.16 & 4.99 & 6.77 & 9.082 \\
\hline Ethanol & $\mathrm{Nd}$ & $\mathrm{Nd}$ & $\mathrm{Nd}$ & $\mathrm{Nd}$ & $\mathrm{Nd}$ & 10.9 & 10.5 & 7.24 & 3.62 & 9.05 \\
\hline
\end{tabular}

${ }^{\mathrm{a}} \mathrm{Nd}$ : not detected.

vehicular emission (Magnusson et al., 2002; Poulopoulos et al., 2001). In this study, a small amount of ethanol was detected in the exhaust from BE-diesel, suggesting that the $5 \%$ ethanol in BE-diesel would not be fully combusted. The similar emission patterns of ethanol and acetaldehyde were observed, indicating that the acetaldehyde in exhaust may mainly originate from the ethanol blended in BE-diesel. The acetone and propionaldehyde emissions from BE-diesel were higher than those from 

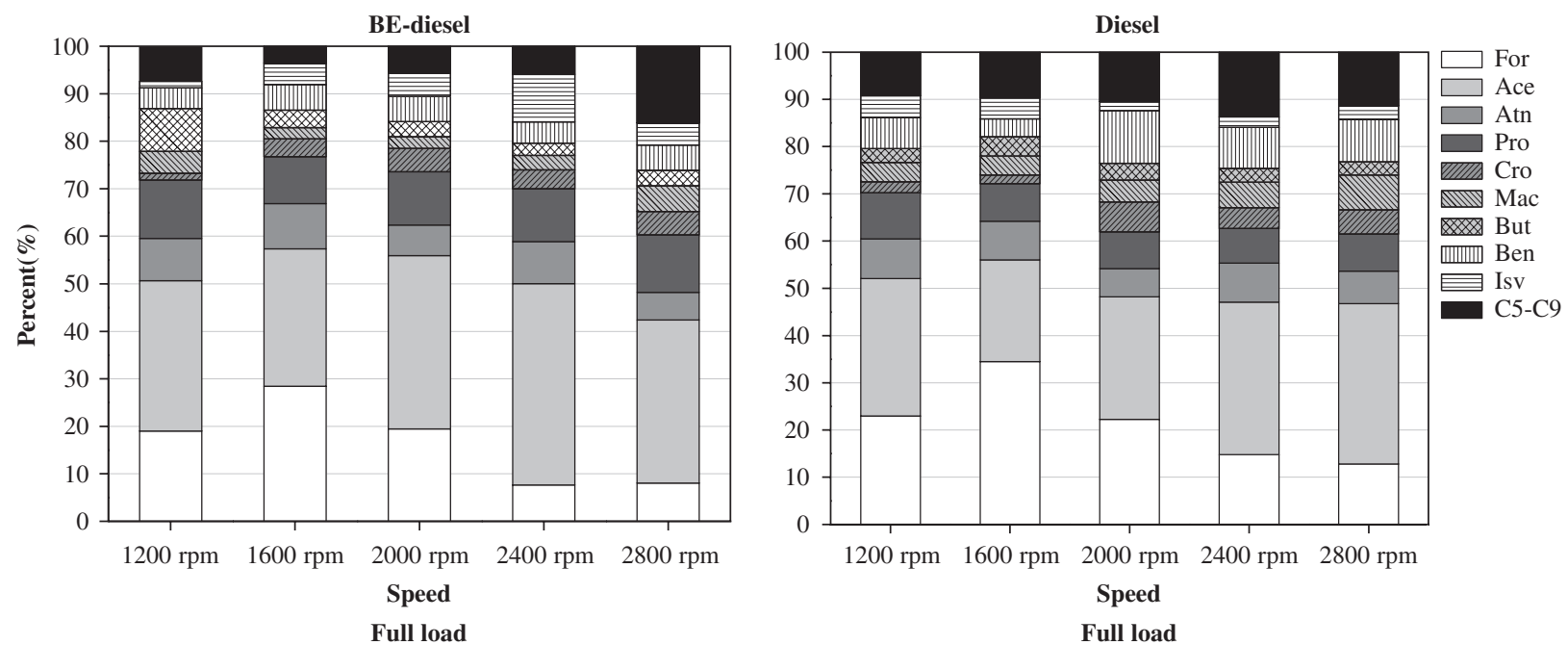

Fig. 1. Percentage of carbonyl compounds in diesel exhaust from BE-diesel and diesel at constant load/varying engine speeds test. For (Formaldehyde), Ace (Acetaldehyde), Atn (Acetone), Pro (Propionaldehyde), Cro(Crotonaldehyde), Mac(Methylacrolein), But(Butyraldehyde), Ben (Benzaldehyde), Isv (Isovaldehyde), C5-C9 ( $m, p$-Tolualdehyde, Hexaldehyde, 2,5-Dimethylbenzaldehyde).
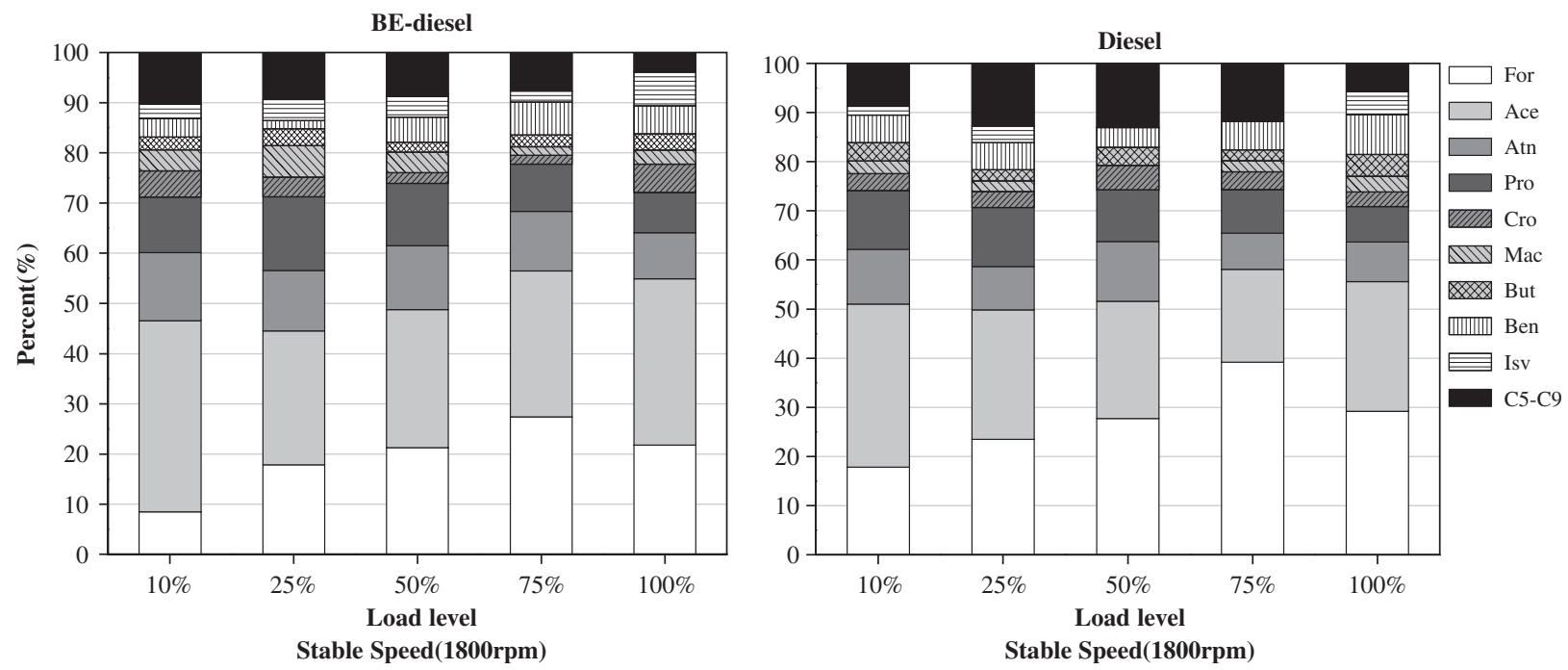

Fig. 2. Percentage of carbonyl compounds in diesel exhaust from BE-diesel and diesel at constant speed/varying loads tests.

diesel. For acetone, the increases varied from $5 \%$ to $85 \%$ and, for propionaldehyde, the increases varied from $13 \%$ to $88 \%$ depending on the engine operating conditions. For crotonaldehyde, methylacrolein, valeraldehyde, isovaleraldehyde, $m$-tolualdehyde, $p$-tolualdehyde, and hexaldehyde, there were no obvious differences in their emissions from BE-diesel and fossil diesel.

The total carbonyls emissions from BE-diesel were slightly higher than those of diesel with increments varying from $1 \%$ to $22 \%$ depending on the engine operating conditions. The slightly higher emission of carbonyls for BE-diesel may be attributed to the oxygenated ester group and ethanol present in the BE-diesel. The result is in agreement with those of the previous studies (Cardone et al., 2002; Gorse et al., 1991; Reuter et al., 1992).

\subsubsection{Effects of engine speed and load level}

As shown in Table 2 and Fig. 3, a positive correlation was found between engine speed and the emissions of acetaldehyde, acetone and propinaldehyde. For other carbonyls, the trends were not so 

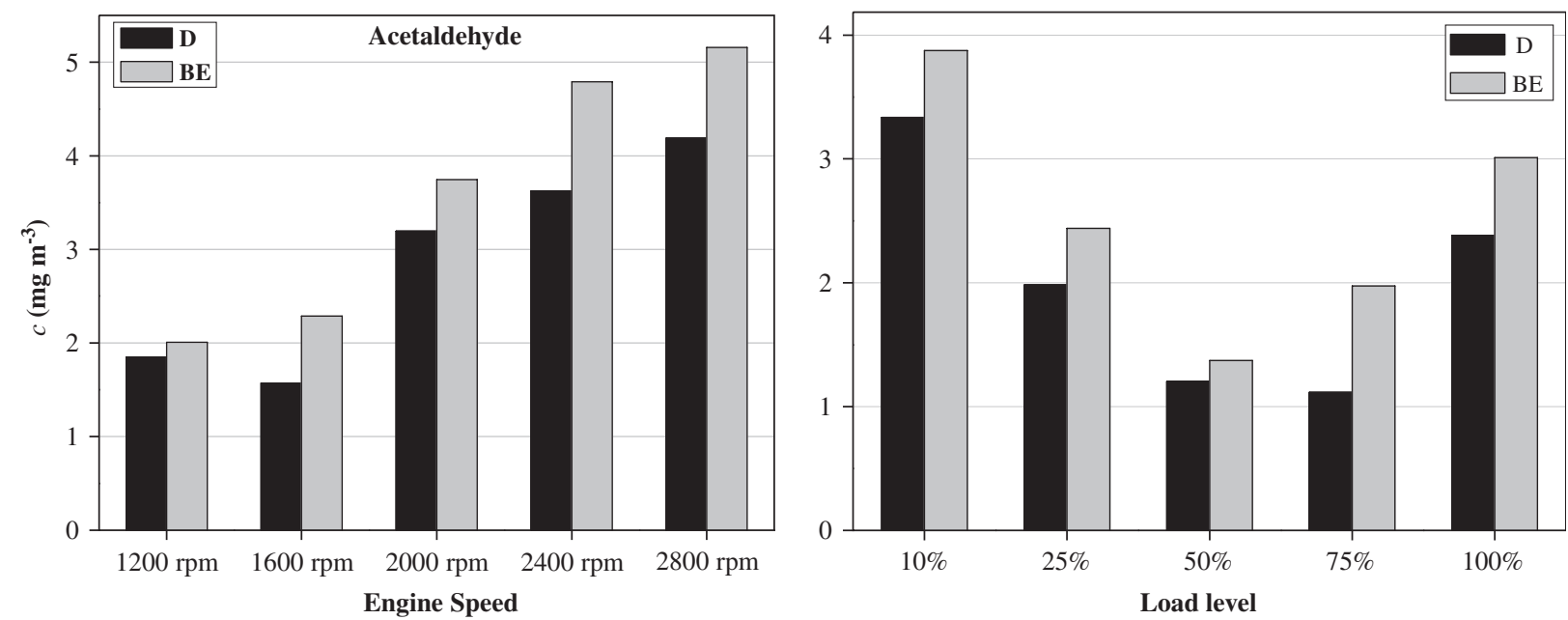

Fig. 3. Acetaldehyde emission under different operating conditions from BE-diesel and diesel.

Table 4

Regulated emissions and PM from diesel and BE-diesel and technical parameters at five engine speeds under full load

\begin{tabular}{|c|c|c|c|c|c|c|c|c|c|c|}
\hline & \multicolumn{10}{|c|}{ Speed (rpm) } \\
\hline & \multicolumn{5}{|c|}{ Diesel } & \multicolumn{5}{|c|}{ BE-diesel } \\
\hline & 1200 & 1600 & 2000 & 2400 & 2800 & 1200 & 1600 & 2000 & 2400 & 2800 \\
\hline \multicolumn{11}{|c|}{ Regulated emissions and PM $\left(g k W h^{-1}\right)$} \\
\hline THC & 1.01 & 0.89 & 0.91 & 0.76 & 0.75 & 0.86 & 0.84 & 0.86 & 0.7 & 0.78 \\
\hline $\mathrm{CO}$ & 3.54 & 1.56 & 2.86 & 2.01 & 2.49 & 3.44 & 1.97 & 2.72 & 1.76 & 1.82 \\
\hline $\mathrm{NO}_{x}$ & 5.89 & 6.25 & 6.00 & 5.82 & 4.77 & 6.69 & 7.35 & 6.74 & 6.66 & 6.41 \\
\hline $\mathrm{CO}_{2}$ & 655 & 605 & 705 & 770 & 788 & 703 & 689 & 688 & 733.7 & 909 \\
\hline $\mathrm{PM}$ & 1.01 & 0.47 & 0.53 & 0.38 & 0.35 & 0.64 & 0.37 & 0.38 & 0.26 & 0.21 \\
\hline \multicolumn{11}{|l|}{ Technical parameters } \\
\hline Power (kW) & 27 & 38 & 47.5 & 52.5 & 53.6 & 25.8 & 37 & 45.6 & 50.6 & 50.9 \\
\hline $\mathrm{SFC}\left(\mathrm{g} \mathrm{kWh}^{-1}\right)$ & 223 & 225 & 226 & 238 & 258 & 235 & 227 & 233 & 247 & 275 \\
\hline Temp. exhaust $\left({ }^{\circ} \mathrm{C}\right)$ & 466 & 498 & 555 & 586 & 621 & 446 & 480 & 521 & 562 & 594 \\
\hline Torque ( $\mathrm{Nm})$ & 215 & 227 & 227 & 209 & 183 & 206 & 221 & 218 & 201 & 173 \\
\hline
\end{tabular}

clear. Because acetaldehyde, acetone and propinaldehyde accounted for high percentage in total carbonyls, the same positive correlation was also found. The total carbonyls emissions increased from about 6.0 to $12.0 \mathrm{mg} \mathrm{m}^{-3}$ for diesel and from 6.0 to $15.0 \mathrm{mg} \mathrm{m}^{-3}$ for BE-diesel when the engine speed increased from 1200 to $2800 \mathrm{rpm}$. The increment of total carbonyls emission may be ascribed to the incremental specific fuel consumption (SFC) with engine speed (Table 4).

It was reported that the load level (air/fuel ratio) of diesel engine could significantly influence carbonyls emission (Magnusson et al., 2002). As shown in Table 3, the total carbonyls emission decreased from $10.0 \mathrm{mg} \mathrm{m}^{-3}$ at the low load $(10 \%$ load) to its minimum about $5.0 \mathrm{mg} \mathrm{m}^{-3}$ at the $50 \%$ load level for both fuels. Then, the total emission increased gradually with the incremental load and reached to about $9.0 \mathrm{mg} \mathrm{m}^{-3}$ at full load. At low load, less efficient combustion would happen due to the high excess air and low cylinder temperature. On the other hand, at high load, incomplete combustion would still happen due to deficient air at low air/fuel ratio despite high cylinder temperature. The minimum emission appeared at middle load, which indicated that the air/fuel ratio at middle load may be the optimal ratio to the fuel combustion. For acetaldehyde, acetone, propionaldehyde, butyraldehyde 
valeradehyde and isovaleradehyde, their emissions showed similar varying tendencies with minimum emissions at $75 \%$ load for diesel fuel, and $50 \%$ load for BE-diesel. This discrepancy may be attributed to the different stoichiometric air/fuel ratio $\left(\alpha_{\mathrm{st}}\right)$ of biodiesel (12.6) and fossil diesel (14.6) (Cardone et al., 2002).

\subsection{Regulated emissions and technique parameters}

The regulated pollutants, including $\mathrm{NO}_{x}, \mathrm{CO}$, and $\mathrm{THC}, \mathrm{CO}_{2}$, and $\mathrm{PM}$, and technique parameters, including power, SFC, exhaust temperature and torque were investigated simultaneously and their data under various operating conditions were listed in Tables 4 and 5, respectively.

\subsubsection{Effect of ethanol-biodiesel blend}

A number of studies have found that ethanolblend and biodiesel-blend would substantially reduce some regulated emissions such as $\mathrm{CO}$ and $\mathrm{PM}$ emissions, but produce higher levels of $\mathrm{NO}_{x}$ concentrations compared with fossil diesel (Starr, 1997; Ali et al., 1995; Durbin et al., 2000). Similar results were also found in this study. The PM emissions were significantly reduced $(22-40 \%)$ for $\mathrm{BE}$-diesel in comparison with diesel. PM formation mainly takes place in the fuel-rich zone at high temperature and pressure, specifically within the core region of each fuel spray. The oxygenated agents blended with diesel can effectively deliver oxygen to the pyrolysis zone of the burning diesel spray resulting in less PM generation (McCormick and Parish, 2001; Wang et al., 2000). Slightly higher
$\mathrm{NO}_{x}$ emission was also observed from $\mathrm{BE}$-diesel than the fossil diesel. Cardone et al. (2002), using engine heat release analysis, found that the heat release would occur in advance when an engine was fueled with biodiesel, and this behavior would generate higher temperatures inside the cylinder during the combustion process. The higher temperature in combustion chamber would be in favor of $\mathrm{NO}_{x}$ formation. THC emissions were found to decrease moderately when the engine was fueled with BE-diesel. There were about $8.8 \%$ reduction at the constant load/varying engine speed tests and about $10.3 \%$ reduction at the constant speed/ varying load tests for BE-diesel compared with fossil diesel. There were no substantial differences between $\mathrm{BE}-$ diesel and diesel for $\mathrm{CO}$ and $\mathrm{CO}_{2}$ emissions.

Compared with fossil diesel, the lower heating value of $\mathrm{BE}$-diesel might be responsible for the lower engine power, lower exhaust temperature, lower torque, and higher SFC than those of fossil diesel (Cardone et al., 2002).

\subsubsection{Effects of engine speed and load level}

During the constant load/varying engine speed tests, it was observed that engine power, exhaust temperature, $\mathrm{SFC}$ and $\mathrm{CO}_{2}$ emission were all positive correlated to the engine speed. On the contrary, the emissions of THC, CO, $\mathrm{NO}_{x}$ and PM decreased with the increase of speed. At lower speed, the fuel combustion is less complete due to the lower air/fuel ratio. As the speed increases gradually, the combustion becomes gradually more complete due to the incremental air/fuel ratio.

Table 5

Regulated emissions from diesel and BE-diesel and technical parameters at five load levels under stable speed (1800 rpm)

\begin{tabular}{|c|c|c|c|c|c|c|c|c|c|c|}
\hline & \multicolumn{10}{|c|}{ Load level $(\%)$} \\
\hline & \multicolumn{5}{|c|}{ Diesel } & \multicolumn{5}{|c|}{ BE-diesel } \\
\hline & 10 & 25 & 50 & 75 & 100 & 10 & 25 & 50 & 75 & 100 \\
\hline \multicolumn{11}{|c|}{ Regulated emissions $\left(g k W h^{-1}\right)$} \\
\hline $\mathrm{THC}$ & 2.73 & 1.49 & 0.83 & 0.72 & 3.97 & 2.71 & 1.4 & 0.83 & 0.71 & 3.84 \\
\hline $\mathrm{CO}$ & 3.83 & 1.84 & 0.81 & 0.94 & 2.37 & 4.78 & 2.06 & 0.86 & 0.97 & 2.26 \\
\hline $\mathrm{NO}_{x}$ & 7.35 & 6.74 & 6.66 & 6.69 & 6.41 & 8.39 & 7.63 & 7.48 & 7.39 & 6.87 \\
\hline $\mathrm{CO}_{2}$ & 909 & 734 & 688 & 689 & 703 & 957 & 737 & 693 & 689.7 & 695 \\
\hline \multicolumn{11}{|l|}{ Technical parameters } \\
\hline Power $(\mathrm{kW})$ & 11.3 & 20.7 & 32.1 & 35.8 & 41.7 & 10.0 & 20.0 & 29.9 & 33.9 & 40.1 \\
\hline $\mathrm{SFC}\left(\mathrm{g} \mathrm{kWh}^{-1}\right)$ & 302 & 252 & 219 & 221 & 227 & 348 & 252 & 242 & 238 & 235 \\
\hline Temp. exhaust $\left({ }^{\circ} \mathrm{C}\right)$ & 245 & 326 & 422 & 459 & 535 & 225 & 308 & 395 & 441 & 512 \\
\hline Torque (N m) & 60 & 110 & 170 & 190 & 221 & 56 & 106 & 160 & 180 & 213 \\
\hline
\end{tabular}


Normally, better combustion can be achieved at high engine speed (Magnusson et al., 2002). This may be the reason why the THC, $\mathrm{CO}, \mathrm{NO}_{x}$ and PM emissions drop with the incremental engine speed.

During the constant speed/varying load tests, the THC, $\mathrm{CO}$ and $\mathrm{CO}_{2}$ emissions, SFC decreased with the incremental load level and reached their minimums at $50 \%$ or $75 \%$ load levels. As discussed above, the varying tendencies of their emissions with load level was attributed to the different air/ fuel ratios, which directly affect on the efficiency of combustion. The engine power and exhaust temperature were in positive correlations with the incremental load level.

\section{Conclusions}

The characteristics of carbonyls and regulated emissions from $\mathrm{BE}$-diesel were investigated in a Cummins-4B diesel engine in comparison with those from fossil diesel. The formaldehyde emissions from BE-diesel were considerably lower than those from diesel because of less apliphatic hydrocarbonys in $\mathrm{BE}-$ diesel. The acetaldehyde emissions from BEdiesel were significantly higher than those from diesel due to ethanol blend. The total carbonyls emissions from BE-diesel were 1-22\% higher than those from diesel. In term of regulated emissions, the BE-diesel was observed to produce obviously lower level of PM and slightly higher level of $\mathrm{NO}_{x}$ compared with the fossil diesel fuel. Although the usage of BE-diesel could slightly increase the emissions of carbonyls and $\mathrm{NO}_{x}$, it also significantly reduce the emissions of PM and THC. In general, compared with fossil diesel, the wide usage of alternative fuel of BE-diesel will be more friendly to the environment.

\section{Acknowledgements}

The authors thank Chunmei Geng and Shuangxi Fang for their kind help during experiment. All authors herein are grateful to the financial support from Innovation Program of the Chinese Academy of Sciences (KZCX3-SW-430, KZCX3-SW-424), the Chinese National Natural Science Foundation (20577064) and National Basic Research Program of China (2005CB422206).

\section{References}

Ajiv, E.A., Singh, B., Bhattacharya, T.K., 2000. Thermal balance of a single cylinder diesel engine operating on alternative fuels. Energy Conversion and Management 41, $1533-1541$.

Ali, Y., Hanna, M.A., Borg, J.E., 1995. Optimization of diesel, methyl tailowate and ethanol blend for reducing emissions from diesel engine. Bioresource Technology 52, 237-243.

Cardone, M., Prati, M.V., Rocco, V., Seggiani, M., Senatore, A., Vitolo, S., 2002. Brassica carinata as an alternative oil crop for the production of biodiesel in Italy: engine performance and regulated and unregulated exhaust emissions. Environmental Science and Technology 36, 4656-4662.

Carlier, P., Hannachi, H., Mouvier, G., 1986. The chemistry of carbonyls in the atmosphere - a review. Atmospheric Environment 20, 2079-2099.

Carter, W.P.L., 1995. Computer modeling of environmental chamber measurements of maximum incremental reactivities of volatile organic compounds. Atmospheric Environment 29, 2513-2527.

Durbin, T.D., Collins, J.R., Norbeck, J.M., Smith, M.R., 2000. Effects of biodiesel, biodiesel blends, and a synthetic diesel on emissions from light heavy-duty diesel vehicles. Environmental Science and Technology 34, 349-355.

Fernando, S., Hanna, M., 2004. Development of a novel biofuel blend using ethnaol-biodiesel-diesel miscroemulsions: EBdiesel. Energy and Fuels 18, 1695-1703.

Gaffney, J.S., Marley, N.A., Martin, R.S., Dixon, R.W., Reyes, L.G., Popp, C.J., 1997. Potential air quality effects of using ethanol-gasoline fuel blends: a field study in Albuquerque, New Mexico. Environmental Science and Technology 31, 3053-3061.

Gerdes, K.R., Suppes, G.J., 2001. Miscibility of ethanol in diesel fuels. Industrial and Engineering Chemistry Research 40, 949-956.

Gorse Jr., R.A., Benson, J.D., Burns, V.R., Hochhauser, A.M., Koehl, W.J., Painter, L.J., Reuter, R.M., Rippon, B.H., 1991. Toxic air pollutant vehicle exhaust emissions with reformulated gasolines. SAE Technique Paper-912324.

Grosjean, D., Grosjean, E., Gertler, A.W., 2001. On-road emissions of carbonyls from light-duty and heavy-duty vehicles. Environmental Science and Technology 35, 45-53.

Magnusson, R., Nilsson, C., Andersson, B., 2002. Emissions of aldehydes and ketones from a two-stroke engine using ethanol and ethanol-blended gasoline as fuel. Environmental Science and Technology 36, 1656-1664.

Makareviciene, V., Sendzikiene, E., Janulis, P., 2005. Solubility of multi-component biodiesel fuel systems. Bioresource Technology 96, 611-616.

McCormick, R.L, Parish, R., 2001. Technical barriers to the use of ethanol in diesel fuel. Milestone Report to NREL/MP-54032674.

Poulopoulos, S.G., Samaras, D.P., Philippopoulos, C.J., 2001. Regulated and unregulated emissions from an internal combustion engine operating on ethanol-containing fuels. Atmospheric Environment 35, 4399-4406.

Reuter, R.M., Benson, J.D., Burns, V.R., Gorse Jr., R.A., Hochhauser, A.M., Koehl, W.J., Painter, L.J., Rippon, B.H., Rutherford, J.A., 1992. Effects of oxygenated fuels and RVP on automotive emissions. SAE Technique Paper-920326. 
Sharp, C.A., Howell, S.A., Jobe, J., 2000a. The effect of biodiesel fuels on transient emissions from modern diesel engines, Part I. Regulated emissions and performance. SAE Technical Paper 2000-01-1967.

Sharp, C.A., Howell, S.A., Jobe, J., 2000b. The effect of biodiesel fuels on transient emissions from modern diesel engines, Part II. Unregulated emissions and chemical characterization. SAE Technical Paper 2000-01-1968.

Shi, X., Yu, Y., He, H., Shuai, S., Wang, J., Li, R., 2005. Emission characteristics using methyl soyate-ethanol-diesel fuel blends on a diesel engine. Fuel 84, 1543-1549.
Starr, M.E., 1997. Influence on transient emissions at various injection timings, using cetane improvers, biodiesel, and low aromatic fuels. SAE Technical Paper-972904.

USA Environment Protection Agency (USA EPA), 1999. Compendium method TO-11A. Determination of formaldehyde in ambient air using adsorbent cartridge followed by high performance liquid chromatography (HPLC) [active sampling methodology].

Wang, W.G., Lyons, D.W., Clark, N.N., Gautam, M., Norton, P.M., 2000. Emissions from nine heavy trucks fueled by diesel and biodiesel blend without engine modification. Environmental Science and Technology 34, 933-939. 